\title{
MEIOS DE COMUNICAÇÃO E INCOMUNICAÇÃO NO PENSAMENTO EDUCACIONAL DE JOHN DEWEY, CÉLESTIN FREINET E PAULO FREIRE
}

RESUMO: O artigo visa problematizar, em abordagem comparada, os conceitos de comunicação no pensamento educacional de John Dewey (1859-1952), Célestin Freinet (1896-1966) e Paulo Freire (1922-1997), particularmente no que diz respeito aos meios de comunicação em suas obras pedagógicas, embora essas tecnologias não tenham sido tema privilegiado em suas considerações sobre o tema comunicação. Os autores tecem críticas aos aparatos comunicativos, pois promoveriam desorientação por excesso de informação, massificação e apelo ao consumo. Todavia, é possível observar nuances analíticas: Dewey acreditava que a mídia ainda poderia retomar seu papel na criação da comunidade social, Freinet encorajava os alunos a apropriarse dos códigos narrativos para entender a lógica midiática e Freire advogava uma Pedagogia da Comunicação.

PALAVRAS-CHAVE: Educação; Comunicação; Mídia; Educação comparada.

\section{COMMUNICATION AND NON-COMMUNICATION MEDIA IN JOHN DEWEY'S, CELESTIN FREINET'S AND PAULO FREIRE'S EDUCATIONAL THOUGHT}

ABSTRACT: The communication concepts in the educational thought of John Dewey (1859-1952), Célestin Freinet (1896-1966) and Paulo Freire (1922-1997) are problematized and compared, especially with respect to communication media, even though technologies have not been prioritized in their ideas on the communication theme. The authors criticize the communication apparatuses due to the ensuing disorientation through excess of information, massification and consumption appeal. However, analytic nuances may be observed: Dewey believed that the media might reassume its role in the establishment of social communication; Freinet encouraged his students to appropriate themselves of narrative codes to understand the logic of the media; Freire insisted on the Pedagogy of Communication.

KEY WORDS: Education; Communication; Media; Comparative education.

Doutora em Educação pela Pontifícia Universidade Católica de Minas Gerais (PUC Minas), Mestre em Comunicação pela Universidade Federal de Minas Gerais (UFMG). Docente e pesquisadora. E-mail: claufon@ gmail.com 


\section{INTRODUÇÃO}

A interface entre Educação e Comunicação é recente, remontando ao século XX. Compreendidas como processos culturais ou mesmo de forma cientificamente organizadas como disciplinas, campos ou áreas de estudo, Educação e Comunicação compõem dinâmicas ambíguas, muitas vezes de atração, integração e reciprocidade; mas o estranhamento, o questionamento e a repulsa mútuas ocorrem também com frequência.

Discorrer sobre a Educação e a Comunicação é tarefa complexa, não apenas pela problemática conceitual e metodológica que se impõe ao estudo e à pesquisa, mas, principalmente, porque são áreas que cada vez mais se implicam mutuamente e precisam "conversar". Embora os processos educativos não ocorram somente nas escolas e os processos comunicativos não tenham lugar unicamente nos meios de comunicação, essas instituições são privilegiadas e reconhecidas socialmente como detentoras de um "poder simbólico", como afirmou o sociólogo britânico J. B. Thompson (2009).

Professores e comunicadores, portanto, necessitam de argumentos e de aporte teórico para que possam lidar com as diferentes situações de intercâmbio que têm surgido no cotidiano das salas de aula e nos espaços extraescolares, em tempos de onipresença das mídias digitais.

$\mathrm{Na}$ História da Educação, alguns autores recorreram explicitamente à comunicação, utilizando o termo como categoria importante para a constituição de seu pensamento educacional/pedagógico. Este artigo é um extrato da tese intitulada A comunicação no pensamento educacional de Jobn Dewey, Célestin Freinet e Paulo Freire: um estudo em perspectiva comparada (2017), cujo objetivo foi justamente contribuir para se pensar a educação em termos comunicacionais e vice-versa, investigando qual é o lugar da comunicação no contexto de determinadas filosofias educacionais, que se desdobraram em práticas pedagógicas.

Ao lançar mão da comunicação para pensar a educação, autores que viveram em tempos históricos distintos e em realidades distintas, reconheceram não somente um fenômeno social novo, mas também construíram abordagens teóricas e metodológicas em que este fenômeno foi tratado como elemento intrínseco. 
O recorte realizado é o de verificar como os autores selecionados examinaram especificamente os meios de comunicação. John Dewey refletiu sobre o papel social da imprensa e do rádio, meios disponíveis à sua época, assim como Célestin Freinet. Já Paulo Freire, falecido em 1997, em algumas passagens referiu-se também à televisão e aos computadores.

\section{COMUNICAÇÃO}

Para compreender de que forma alguns expoentes do pensamento educacional trataram a comunicação, é necessário discorrer sobre o termo. O que é a comunicação? Comunicar-se é o mesmo que informar ou estar informado? As mídias comunicam ou informam?

Tentar definir 'comunicação' é embaraçoso, uma vez que a palavra é polissêmica. Um dos motivos apontados pelo teórico da comunicação Luiz Martino (2003, p. 12) seria que os usos atuais da palavra não guardam mais relação com seu sentido original, que remonta à Idade Média. Naquela época, o termo ‘comunicação', advindo do latim communicatio, referia-se a uma atividade realizada conjuntamente - a refeição nos mosteiros - momento em que os monges se reuniam.

Ainda que muitas vezes os monges guardassem o voto de silêncio às refeições, a ideia de conversação marcou a noção inicial de comunicação, que persiste até os dias de hoje associada a ideias como diálogo e co-presença de interlocutores, mesmo que essas dimensões não sejam suficientes para descrever e/ou explicar a importância da comunicação em nossa sociedade.

Por que nos comunicamos? Para que serve a comunicação? A resposta inicial, para o senso comum, seria a necessidade de sobrevivência. O ser humano, no entanto, não é uma espécie que apenas se abriga, busca alimento e água. Buscamos sentido e o atribuímos à nossa existência, aos fenômenos naturais que nos cercam e à nossa convivência com os outros.

Adriano Rodrigues (2012, p. 13), teórico da comunicação, afirma que "para os seres humanos o mundo não é nunca propriamente a realidade, mas o resultado da constituição de processos de objetivação simbólica." Somos animais simbólicos. 
Nas ciências humanas, especialmente na Antropologia Social, autores como Leach (1992) e Geertz (1989) debruçaram-se sobre o tema da comunicação - tanto em seus aspectos verbais como não-verbais - como um elemento que simultaneamente instaura e é instaurado pela cultura.

Se mesmo a comunicação face a face - em que os interlocutores se encontram em co-presença - apresenta diversas sutilezas e variáveis difíceis de compreender, a comunicação coletiva impõe maiores desafios ao observador. É justamente na emergência de um novo tipo de comunicação - a comunicação social - que se instaura uma distinção radical no significado do termo. Com efeito, aquilo que chamamos 'comunicação' atualmente - desde a invenção dos meios tecnológicos guarda muito pouca semelhança com a concepção do 'communicatio'.

A própria palavra, de acordo com Martino, entrou em desuso durante séculos, sendo recuperada somente no século XVIII, com a significação modificada. Comunicação, a partir de então, passa a ser um termo-síntese para se descrever as diversas maneiras de se estabelecer relação com outrem, mediadas pela linguagem. O emprego atual do termo "comunicação" é polissêmico, uma vez que as situações e os recursos de comunicação atingiram um grau enorme de presença e complexidade na vida cotidiana. A comunicação pode ser entendida como discurso, informação, técnica social ou processo, dependendo da situação e/ou circunstância em que ocorre, ainda segundo Martino (2003).

Para a pesquisadora em comunicação portuguesa Isabel Ferin (2002), a relevância que a comunicação adquire na contemporaneidade pode ser explicada tanto por processos culturais mais amplos, que "acompanham a história da expansão da Europa no século XIX e do Ocidente no século XX" (p. 18), como por acontecimentos mais estreitamente ligados ao fenômeno:

o conceito moderno de comunicação tem as suas raízes mais próximas quer nos movimentos culturais, científicos, religiosos e econômicos que antecederam as grandes viagens marítimas dos séculos XV e XVI, quer nas alterações culturais, sociais, políticas e econômicas desencadeadas logo após o estabelecimento destes acontecimentos (FERIN, 2002, p. 17).

A expansão do Capitalismo por toda a Europa, a consolidação dos impérios coloniais europeus, a criação de sofisticadas tecnologias militares, o desenvolvimento 
da infraestrutura e dos meios de transporte, a progressiva urbanização, entre outros fatores, foram a base mais ampla sobre a qual "se desenvolveram as redes técnicas, complexificaram-se os processos de distribuição, partilha e utilização de matéria simbólica no espaço público" (FERIN, 2002, p. 19).

O notável desenvolvimento das comunicações, como fluxo de informação, dentro desse contexto de transformações materiais e institucionais impulsionadas pelo Capitalismo, como sistema econômico que foi tornando-se dominante, aconteceu pela conjunção de três realidades: a imprensa, a propaganda e a expansão do espaço público.

É no processo de racionalização dos espaços que as vontades, interesses e expressões dos indivíduos são colocados em cena, por meio da argumentação racional de maneira a transformar - pelo menos idealmente - interesses privados em consensos coletivos. Daí a crescente importância da imprensa e da propaganda como instrumentos de formação, consolidação e legitimação das opiniões.

Isso porque, segundo esclarece J. B. Thompson (2009), observa-se, nesse período - a modernidade - uma mudança "profunda e irreversível", uma transformação na natureza da produção e do intercâmbio simbólico no mundo moderno: em virtude desses desenvolvimentos, as formas simbólicas foram produzidas e reproduzidas em escala sempre em expansão; tornaram-se mercadorias que podem ser compradas e vendidas no mercado; ficaram acessíveis aos indivíduos largamente dispersos no tempo e no espaço (THOMPSON, 2009, p. 19).

$\mathrm{O}$ autor chama a atenção para o fato de que tão logo "estas transformações começaram a acontecer, adquiriram uma energia própria". (THOMPSON, 2009, p. 47). O fenômeno comunicacional constitui-se como um fenômeno social e, algumas décadas mais tarde, talvez pelo impacto que gerou no meio social, um campo de conhecimento científico.

Em síntese, a comunicação é um processo social básico que adquire uma nova configuração na contemporaneidade, a partir da emergência tecnológica, criando um aparato socialmente instituído: os meios de comunicação. Atualmente, os conceitos de comunicação e de informação na prática se confundem, porque estão entrelaçados no universo midiático. Marcondes Filho (2014) afirma que "a vivência cotidiana confunde a mera troca de sinais com comunicação". 
$\mathrm{O}$ autor utiliza como exemplo a frase "sou comunicado de que o sr. Fulano faleceu" para esclarecer que, neste caso, mesmo que o verbo utilizado tenha sido o "comunicar", estamos diante de uma informação. Nada se diz ou se sabe a respeito da relação entre o falecido e os interlocutores, os sentimentos suscitados pela perda ou até se a frase foi compreendida ou esquecida. O intercâmbio informativo se verifica na representação linguística de uma relação fática.

De acordo com o referido autor, a comunicação, ao contrário, é algo que somente pode acontecer ao receptor, porque implica em uma afetação:

O filme me comunicou, no sentido de que me alterou, me provocou, me incomodou, perturbou minha estabilidade de um sistema fechado. No momento em que me expus ao Outro, à alteridade radical que ele portava, algo aconteceu nesse encontro que levou ao desarranjo. Trata-se de um acontecimento comunicacional (MARCONDES FILHO, 2014).

Para efeito conceitual, portanto, pode-se afirmar que a informação trata de um processo de transmissão de sinais, de dados; enquanto a comunicação é um processo que leva em conta a interação profunda entre um eu e a alteridade. A informação é mediada por algum tipo de linguagem, que é ordenada segundo alguma lógica estratégica; a comunicação "simplesmente acontece" (MARCONDES FILHO, 2014).

\section{OS MEIOS DE COMUNICAÇÃO NO PENSAMENTO EDUCACIONAL DE DEWEY}

Educar é um processo que envolve comunicação, pois gera uma interação mediada por algum tipo de linguagem. Na História da Educação ou das Práticas Pedagógicas, no entanto, essa associação íntima entre comunicação e educação nem sempre foi reconhecida. Um dos motivos, certamente, é que o aluno - criança e adolescente - não era considerado, até meados do século XVIII, como sujeito. Ora, se não era sujeito, também não era admitido como interlocutor.

A pedagogia tradicional assentava-se na concepção de organização da educação, com a autoridade do mestre. Somente com o advento do movimento conhecido como Escola Nova, iniciado na segunda metade do século XIX, considera- 
se o aluno como alguém que detém a palavra no processo educativo. É uma tomada de posição frente ao ato educativo: "a infância tem um valor positivo que o adulto não deve afetar: a criança tem uma forma particular, e o adulto não pode agir sobre ela”. (COUSINET, 1976, p. 93). O conhecimento prévio do educando, assim como o contexto de experiência passaram a ser elementos vivos do processo educativo.

É importante compreender, contudo, que a Escola Nova - também denominada Pedagogia Nova, Educação Nova, Escola Ativa, Escola Moderna, etc. - foi um movimento pedagógico multiforme, no interior do qual um amplo espectro de posições políticas e ideológicas se viu representada. Apesar de congregar múltiplas iniciativas no campo educacional e diversos jeitos de "fazer a escola" que traduziram concepções de mundo e de sociedade bastante variadas, o movimento da Escola Nova teve como característica principal a afirmação científica da Pedagogia, como disciplina que se contrapunha aos velhos métodos de educar.

O termo Educação Nova foi utilizado pela primeira vez em 1989, com a publicação do livro A Educação Ativa, de Adolf Ferrière. De acordo com o historiador da Educação Mario Manacorda, para o movimento Escola Nova confluíram duas grandes linhas de mudança na relação educação-sociedade:

A relação educação-sociedade contém dois aspectos fundamentais na prática e na reflexão pedagógica moderna: o primeiro é a presença do trabalho no processo da instrução técnico-profissional, que agora tende para todos a realizar-se no lugar separado "escola", em vez do aprendizado no trabalho, realizado junto aos adultos; o segundo é a descoberta da psicologia infantil com suas exigências "ativas". Estes dois aspectos tem entre si relações mais profundas do que possa parecer a uma primeira consideração, embora na prática essas duas exigências pedagógicas sejam divergentes, como já vimos. Estes dois aspectos disputam o grande e variado movimento de renovação pedagógica que se desenvolve entre o fim dos Oitocentos e o início do Novecentos, na Europa e na América (MANACORDA, 1995, p. 305).

Dentro dos autores escolanovistas, o norte-americano John Dewey é considerado um dos principais articuladores filosóficos do movimento. Com uma obra profícua e vasta como seus 96 anos de vida, Dewey não somente ofereceu um testemunho de época, como também interpretou e analisou diferentes aspectos das transformações sociais, de tal modo que as dimensões filosófica, política e educacional de seus escritos formam um todo harmônico e coerente. 
Os conceitos de reconstrução, de experiência, de democracia e de pensamento reflexivo são os princípios estruturantes do pensamento dewelyano e encontram-se habilmente desenvolvidos e entrelaçados em seu raciocínio.

Para o referido teórico, a educação, que acontece por meio de uma variedade de experiências genuínas, tem como característica essencial ser um processo compartilhado e, por isso mesmo, comunicacional (DEWEY, 1970). Nessa perspectiva, a qualidade da experiência está diretamente ligada à possibilidade e efetividade da comunicação.

Quanto mais a escola for uma instituição capaz de promover a comunicação em todas as suas dimensões - entre alunos; entre alunos e professores - entre pais e escola; e, por fim, entre escola e sociedade - mais ela fomentará as experiências educativas para os envolvidos.

Os meios de comunicação social, no entanto, nem sempre contribuiriam para a melhoria da qualidade da experiência social. Dewey foi um dos primeiros autores a utilizar a acepção contemporânea do termo "comunicação". Foi também um dos primeiros a utilizar o termo "meios de comunicação" em inglês. De acordo com Varão (2014), no livro The School and the Society (1900), o pedagogo norteamericano assim descreve o desenvolvimento da mídia e seu impacto social:

A imprensa foi inventada, tornou-se comercial. Livros, revistas, jornais se multiplicaram e ficaram mais baratos. Como consequência da locomotiva e do telégrafo, a intercomunicação rápida e barata pelo correio foi possível. Viajar é agora considerado fácil, liberdade de movimento a acompanham. Troca de ideias, facilitada indefinidamente. O resultado tem sido uma revolução intelectual. O aprendizado tem sido posto em circulação. Enquanto isso acontece, e provavelmente sempre continuará acontecendo, uma classe específica tenta deter o conhecimento. Uma classe distinta detentora do conhecimento será doravante fora de questão. É um anacronismo. O conhecimento não é mais sólido, ele está disperso (liquefeito). Ele está se espalhando ativamente, em todos os âmbitos sociais (tradução nossa). (DEWEY apud VARÃO, 2014, s/n).

Na referida citação, o autor demonstra que nem sempre o desenvolvimento tecnológico encontra-se sintonizado com a democratização das relações sociais. De fato, no caso da comunicação social, a invenção dos meios de comunicação não significou necessariamente um incremento no conhecimento coletivo - 
pelo contrário - uma vez que grande parte do seu conteúdo é constituída por entretenimento com finalidade comercial. Desta forma, a abundância de meios de informação pode até dificultar a formação da opinião pública, em vez de favorecê-la, uma vez que quantidade e qualidade de informação não se equivalem:

Os novos mecanismos, resultantes da aplicação das descobertas científicas, estenderam imensamente a quantidade e a variedade de acontecimentos particulares, ou seja, "itens de notícias", que passaram a ser trazidos aos sentidos e às emoções ligadas a eles. O telégrafo, o telefone e o rádio relatam acontecimentos que passam na face inteira do globo. São, na sua maior parte, fatos sobre os quais os indivíduos que os recebem nada podem fazer, a não ser reagir com uma passageira excitação emocional. Porque, devido à falta de relação e organização entre uns e outros, não é possível nenhuma representação imaginativa da situação capaz de suprir a ausência de resposta pessoal (DEWEY, 1970, p. 136).

A separação espacial e temporal entre o aparato de comunicação e o público geram novas características que desafiam as sociedades modernas. Em Liberalismo, liberdade e cultura (1970), Dewey discorreu sobre a centralidade da comunicação para a investigação social democrática e, nesta obra, refere-se à comunicação não apenas como um conceito, mas também como o aparato tecnológico e social conhecido como imprensa. Esta pode fomentar um descompasso entre a experiência imediata e cotidiana e a experiência social:

A imprensa, o telégrafo, o telefone e o rádio alargaram indefinidamente a ordem de informações à disposição da pessoa comum. Seria inépcia negar que disto resultou certo despertar de mentes naturalmente indolentes. Mas, pondo-se inteiramente de lado o fato de se terem aberto novas avenidas pelas quais pode continuamente operar a propaganda organizada para despertar a emoção e deixar atrás de si um saldo de opinião - cabe notar que há muita informação sobre que o juízo não é solicitado a responder, e que, mesmo se o quisesse fazer, não seria efetivamente possível, tão dispersivo é o material sobre que seria chamado a se aplicar (DEWEY, 1970, p. 137).

Os meios de comunicação, para Dewey, impedem o pensamento reflexivo, tal o modo pelo qual se estrutura sua dinâmica de funcionamento. Segundo ele, "a dispersão" característica da informação faz com que tenhamos muito com que 
nos ocupar, mas como não podemos intervir no curso dos acontecimentos, nos sentimos muito mais atribulados que esclarecidos, quando não desnorteados.

Outro aspecto importante a considerar sobre os meios de comunicação, além da mudança cultural descrita acima, seria a dependência econômica. Para o autor, a sociedade democrática fundamenta-se sobre a opinião coletiva, formada pelo público. A possibilidade da existência e da manifestação desse público é precondição para a vida democrática. Os meios de comunicação seriam a instância aonde a voz desse público poderia ser ouvida. Em determinado trecho do livro, faz uma crítica à imprensa que, no seu modo de ver, apesar de se sustentar pela existência de um público, não o privilegiaria:

Além do fato de que a imprensa pode distrair com trivialidades a atenção pública, ou ser um agente faccioso, ou instrumento para inculcar ideias em apoio a interesses ocultos de um grupo ou classe (tudo em nome do interesse público); além disso, a realidade presente em todo o mundo é tal, a esse respeito, que o indivíduo se sente esmagado e emocionalmente confuso ante a reverberação de uma publicidade sensacionalista de acontecimentos isolados (DEWEY, 1970, p. 134).

Para o autor, a imprensa, quando age estritamente em conformidade com seus interesses econômicos, por ser ela mesma parte interessada no lucro, perde de vista $\mathrm{o}$ interesse público, torna-se propaganda e desserve à democracia. $\mathrm{O}$ caráter mediador da imprensa, segundo Dewey, deve ser exercido na perspectiva do coletivo, de modo que todos os interlocutores interessados em uma questão tenham voz. O balanço entre interesses individuais e coletivos, que é um pressuposto da democracia, fica ainda mais difícil de ser alcançado.

De acordo com Mendonça (2013), o raciocínio de Dewey vai caminhando da ideia de indivíduo para a noção de público. Quanto mais tem a possibilidade de se expressar nos marcos de uma sociedade democrática, mais o público exercita suas condições de comunicabilidade, o que por sua vez pode acarretar transformações sociais. Para que tenha condições de expressão, o público necessita de informação fidedigna. Daí a importância dos meios de comunicação, desde que não exorbitem sua função e se submetam, eles também, aos parâmetros de uma sociedade democrática. 
Para Dewey, a imprensa, como aparato coletivo de comunicação, não pode ser um obstáculo à formação do público. Como instituição, deveria trabalhar em benefício dele, acolhendo a multiplicidade de suas manifestações, de modo a colocálas para debate. A imprensa necessita de um sistema democrático sólido para existir e a recíproca é verdadeira.

\section{FREINET E OS MEIOS DE COMUNICAÇÃO}

O pedagogo francês Célestin Freinet é conhecido na história da educação como pioneiro na utilização de meios de comunicação na escola. É preciso ter cuidado, no entanto, para compreender a visão freinetiana a respeito da comunicação - como processo social - e os meios de comunicação - como instituições sociais informacionais. $\mathrm{O}$ autor percebeu esta distinção.

Freinet adota uma perspectiva dialógica da comunicação recusando, em suas obras, qualquer forma de autoritarismo aberta ou velada. A horizontalidade que preconiza para as relações humanas é construída por meio do trabalho cooperativo, num ambiente que reconcilia razão e afetividade. Em alguns pontos de sua obra, principalmente nos últimos livros, nos quais se destaca uma perspectiva mais vitalista, o autor tende a valorizar o meio natural como ideal educativo.

Essa reflexão é importante, porque ajuda a compreender a relação entre educação e comunicação na obra freinetiana. "O autor se oporá à ciência e às técnicas modernas sempre que forem veículos de discriminação e não de cooperação, de morte e não de vida, de arbitrariedade e não de harmonia, de submissão e não de liberdade" (NASCIMENTO, 1995, p. 40).

Em seus livros, entre eles Para uma escola do povo (1973) e Pedagogia do bom senso (1967) Freinet, por vezes, parece ter um posicionamento ambíguo sobre os meios de comunicação coletiva. Verifica-se que o pedagogo busca examinar dialeticamente a tecnologia comunicacional na sociedade contemporânea. Ela tanto pode exercer uma influência consumista, ideológica, "embrutecedora" - nas palavras do autor - como também ter uma potencialidade emancipatória. A utilização dos meios de comunicação na escola nunca é gratuita, revela-se um ato pedagógico 
e político intencional. Freinet lança uma importante questão sobre as relações entre a escola e o meio:

Em que medida é que a educação periescolar auxilia a ação da escola? Há a máxima necessidade de se ter em conta a influência da família em regime capitalista, e a influência de todas as forças obscurantistas cujos esforços se conjugam no sentido da manutenção de uma ordem social única: o cinema, o rádio, a imprensa - com os seus jornais para crianças e seus livros alienatórios para adultos - os seus livros de cordel e as suas revistas malsãs [...] (FREINET, C. apud FREINET, E., 1978, p. 281).

Em resposta à questão por ele mesmo formulada, Freinet não foge à contradição colocada pela presença dos meios de comunicação na sociedade, convocando os professores a enfrentá-la:

Apesar de todas as forças reacionárias e contra elas, os professores primários devem erguer o seu protesto na sua dupla condição de cidadãos e de educadores decididos a integrar completamente a sua tarefa no processo histórico da evolução social (FREINET, C. apud FREINET, E.,1978, p. 281).

Para Freinet, os meios de comunicação são tecnologias inventadas com sentido preciso de distração, de alienação dos problemas colocados pelo modo de vida capitalista. Os meios audiovisuais como o rádio, o cinema e a televisão, por representarem um aperfeiçoamento desse tipo de tecnologia, precisam ser vistos com mais cuidado ainda. Por isso, cabe ao educador exercer a intencionalidade pedagógica, reconhecendo a presença dos meios e sua importância na vida das crianças, mas, ao mesmo tempo, exercendo uma crítica sobre eles, numa visão emancipatória. Ao comentar sobre o rádio escolar, por exemplo, disse o autor:

Também nos agrada constatar que as emissões de rádio vão passar de simples distrações que são para autênticas lições. Apenas se trata de um outro tipo de lições que terão que ser concebidas de acordo com uma nova técnica. Essa técnica é a que nós preconizamos e preparamos. Não teremos dificuldade em completar os elementos de estudo que nos trazem as ondas escolares graças ao nosso ficheiro e à nossa biblioteca de trabalho. É aí que se revela a importância e a necessidade destes novos utensílios (grifo nosso) FREINET, C. apud FREINET, E., 1978, p. 407). 
Freinet não utilizou o termo indústria cultural, tal qual proposto por Adorno e Horkheimer, mas, ao refletir sobre a imprensa e os meios de comunicação audiovisuais demonstrou perspicácia na compreensão do lugar e do movimento dessas técnicas no mundo atual. Percebeu o quanto a disseminação dos mass media se constituiu em um elemento central ao desenvolvimento do capitalismo, utilizando-se de estratégias como a sedução do público para distraí-lo e aliená-lo (efeito haxixe, para usar o vocabulário freinetiano). Por outro lado, teve a ousadia de pensar pedagogicamente a utilização desses mesmos meios de comunicação, uma vez que fazem parte do mundo e da vida da criança:

É óbvio que não preconizamos a Imprensa Escolar unicamente como processo técnico de impressão de textos úteis à leitura global. O que nós pretendemos é que a vida das crianças passe realmente para o centro da aula através da Imprensa Escolar e que se abandonem definitivamente todos os exercícios escolásticos novos ou antigos, que serão proveitosamente substituídos pela atividade alegre e livre (FREINET, C. apud FREINET, E., 1979, p. 195).

O trecho acima confirma que o conceito de técnica freinetiana, como parte que, embora tenha finalidade nela mesma, converge com outras para uma finalidade maior, guiada por uma perspectiva política da educação. É a vida "real" das crianças que deve ser o centro da escola e não o próprio jornal, mas sem este não se alcança aquela.

\section{PAULO FREIRE E A PEDAGOGIA DA COMUNICAÇÃo}

Para o entendimento do conceito de comunicação em Freire, é necessário considerá-lo não como transferência ou transmissão de conteúdos, mas em suas dimensões simultaneamente simbólica e gnosiológica. Para ele, "comunicar é comunicar-se em torno do significado significante" (FREIRE, 2010, p. 67).

A frase acima destaca o caráter teórico-prático da comunicação. Quando alguém se comunica, não o faz somente porque tem a intenção, mas realiza, de fato, uma ação. Esta ação, possibilitada pelo contexto cultural, o qual fornece um código, um motivo e um significado, de certa forma, também a limita. O significado é 
compartilhado, ensejando vários outros atos comunicativos, eles também formados e informados culturalmente. Desse intenso processo de interlocução, forma-se um sentido "o significado significante".

O mundo humano é um "mundo de comunicação", afirma Freire (2010, p. 66) baseando-se na obra do filósofo espanhol Eduardo Nicol (1907-1990). A comunicação faz a mediação entre os seres humanos, desta forma não somente nomeia o mundo, mas também o representa e o projeta. O ser humano não se serve da comunicação, como se fora um instrumento: comunicar-se é entrar em atividade com outros "um encontro entre homens, mediados pela palavra, a fim de dar nome ao mundo" (FREIRE apud LIMA, 1984, p. 65). A ação leva à reflexão, de modo que os homens, em diálogo, (re)fazem seu mundo.

É por isso que não se pode "transferir" ou "doar" comunicação. Para Freire, o ato comunicativo pressupõe a atividade de pessoas "que tem voz" e a quem seja facultado expressar-se. A comunicação que é imposta, sob qualquer pretexto, seria apenas "comunicado", fruto de um processo equivocado de "extensão". O ato comunicativo tem, em Freire, uma importância semiótica fundamental. O sentido de qualquer troca comunicativa não é inferido somente pelos atos de codificação ou decodificação, como reconhecimentos da palavra. É alfabetizado aquele que lê o mundo, interpreta-o, dá sentido a ele, incorpora-o.

Com alguma liberdade hermenêutica, considerar o termo "alfabetização" como uma metáfora do ato de constituição do sujeito. Seria alfabetizado aquele que domina sua expressão, sua palavra. O referido autor (2010, p. 69) também afirmou que "a educação é comunicação, é diálogo, na medida em que não é transferência de saber, mas um encontro de sujeitos interlocutores que buscam a significação dos significados".

Ora, em termos semióticos, a frase quer dizer que o sentido não é dado de antemão, é construído "na" e "pela" troca comunicativa. Cada interlocutor precisa ser considerado pelo outro como "sujeito" para que haja efetiva interação. Eles se encontram em um contexto que nunca é neutro, mas situado em condições espaço temporais determinadas. E buscam em conjunto a "significação dos significados", em processo que a um só tempo reconhece, identifica, nomeia, representa e idealiza o mundo. O objetivo da comunicação não seria o de promover o consenso, mas 
de provocar o atrito, para que dele se extraia o sentido, este sempre negociado e provisório.

Paulo Freire não pretendeu estudar os meios de comunicação mas, na medida em que o processo comunicacional fundamentava sua obra, não pode se furtar de escrever sobre os meios. No Brasil, a disseminação de meios comunicativos foi realizada de modo antidialógico, para utilizar uma expressão freireana. A emergência dos segmentos urbanos trouxe novos problemas à já desigual e autoritária sociedade brasileira. O homem urbano, distante de sua origem, desenraizado, busca explicação para a realidade em que passa a viver.

Desse modo, na análise de Freire, a sociedade brasileira passou do modo de vida rural - marcado pela exclusão política e pelo analfabetismo - para outro modo de vida, urbano, tornando-se uma sociedade de massas. A massificação igualmente se torna uma forma de exclusão. O autor explica a massificação como o resultado de um processo em que, apesar da presença de diversos meios e técnicas de comunicação, não se forma "um terreno comum aos polos da relação" (FREIRE, 2010, p. 72). Freire chama a atenção para a vocação transmissiva dos meios de comunicação, que ele denomina "meios de comunicados":

O homem massificado é igualmente impedido de conscientizar-se, uma vez que, apesar de aparentemente usufruir de um contexto modernizado, dele não participa como agente decisório. Está à mercê de diferentes formas de manipulação, que vão do sectarismo político ao fanatismo religioso. Sua consciência é pervertida. "Daí a sua identificação com formas míticas de explicação do seu mundo. Seu comportamento é o do homem que perde dolorosamente o seu endereço. É o homem desenraizado" (FREIRE, 1976, p. 91).

Os meios de comunicação, embora possam multiplicar as chances de promoção do diálogo, paradoxalmente, para Freire, embotam-no. Compromissados com a opressão, tornam-se um de seus principais agentes. Ao vender a ilusão da liberdade, aprisionam. Segundo o autor, a lógica dos meios de comunicação pautase pela incomunicação. Fica claro que o pensamento freireano foge de esquemas tradicionais, tanto na Teoria da Comunicação quanto na Filosofia da Educação.

O aporte técnico que a comunicação humana recebe quando da invenção dos meios de comunicação não leva automaticamente a uma elevação qualitativa desse 
processo. A comunicação, enquanto atividade humana e os meios de comunicação, enquanto dispositivos técnicos, podem não atender à mesma finalidade. Por isso a relevância, para o autor, de uma leitura crítica da comunicação e de uma pedagogia da comunicação.

\section{CONSIDERAÇÕES FINAIS}

Se há um aspecto em comum que nos chama a atenção para os três autores é a recusa, por princípio, de uma concepção naturalizada da comunicação humana. Nenhum deles pode ser associado ao paradigma informacional, segundo o qual a comunicação seria uma atividade de transmissão de conteúdo. O postulado informacional pensa o ato comunicativo de uma maneira linear - como a ideia de "extensão", tão bem posta por Freire e criticada por ele - assemelhando-o a um ir-evir de dados, de sinais, cujo horizonte seria a eficiência.

Descarta-se o contexto no qual a comunicação é realizada, a riqueza do universo semântico e as intrigantes possibilidades de intenção e significado. No paradigma informacional não há lugar para o diálogo. Tanto Dewey, quanto Freinet e Freire vão construindo, ao longo de suas obras, uma concepção do campo comunicacional que leva em conta, sobretudo, a perspectiva cultural. Trata-se de uma abordagem humanista e não-positivista do fenômeno.

Pensar a comunicação em uma perspectiva cultural, portanto, implica em: i) considerar a comunicação como atividade eminentemente humana e, como tal, contextualizada em um tempo e um espaço determinados; ii) reconhecer sua dimensão simbólica, sua imersão no mundo da linguagem, no qual os sentidos não são constituídos a priori, mas no momento mesmo da relação entre os interlocutores; iii) admitir suas correlações com todas as formas de atividade social. Uma abordagem que privilegia a cultura levará em conta os aspectos históricos, porque considera que nenhum meio, forma, modalidade ou circunstância comunicativa é atemporal e ahistórica.

Também se constitui em uma recusa a qualquer redução da comunicação à informação pura, entendida como dado que deve ser trabalhado de forma técnica, com a única finalidade de se conseguir eficiência operacional. 
Pode-se afirmar, portanto, que Dewey, Freinet e Freire concebem a comunicação como relação pedagógica (e, portanto, social e política), materializada pela linguagem, em um contexto determinado. Evidencia-se a importância, então, da escola como lugar em que a comunicação ocorre, concorrendo (ou não) para a constituição da cidadania infanto-juvenil.

\section{REFERÊNCIAS}

DEWEY, J. Liberalismo, liberdade e cultura. São Paulo: Ed. Nacional/USP, 1970.

FERIN, I. Comunicação e culturas do cotidiano. Lisboa, Portugal: Quimera, 2002.

FREINET, C. Pedagogia do bom senso. Lisboa, Portugal: Moraes Editores, 1967.

FREINET, C. Para uma escola do povo: guia prático para a organização material, técnica e pedagógica da escola popular. Lisboa, Portugal: Presença, 1973.

FREINET, É. Nascimento de uma pedagogia popular: os métodos Freinet. Lisboa, Portugal: Estampa, 1978.

FREINET, Élise. O Itinerário de Célestin Freinet: a livre expressão na pedagogia Freinet. Rio de Janeiro: Francisco Alves, 1979.

FREIRE, P. Pedagogia do Oprimido. 3. ed. Rio de Janeiro: Paz e Terra, 1976.

FREIRE, P. Pedagogia da Autonomia: saberes necessários à prática educativa. São Paulo: Paz e Terra, 2010 (Coleção Leitura).

GEERTZ, C. A Interpretação das Culturas. Rio de Janeiro: LTC, 1989.

LEACH, E. Cultura e Comunicação. Lisboa, Ed. 70, 1992. 
LIMA, V. Comunicação e Cultura: as ideias de Paulo Freire. 2. ed. Rio de Janeiro: Paz e Terra, 1984.

MANACORDA, M. História da Educação: da antiguidade aos nossos dias. 4. ed. São Paulo: Cortez, 1995.

MARCONDES FILHO, C. Ensaio sobre a Incomunicação. Alaic, v. 9, n. 17, 2014.

MARTINO, L. De qual comunicação estamos falando? IN: HOHLFELDT, A; MARTINO, L; FRANÇA, V (Org.). Teorias da Comunicação: conceitos, escolas e tendências. 3. ed. Petrópolis: Vozes, 2003.

MENDONÇA, R F. A Liberdade de expressão em uma chave não dualista: as contribuições de John Dewey. IN: GUIMARAES, J; AMORIM, A P (Org.). A Corrupção na opinião pública: uma defesa republicana da liberdade de expressão. São Paulo: Boitempo, 2013.

NASCIMENTO, M. E. A Pedagogia Freinet: natureza, educação e sociedade. Campinas/SP: Ed. Unicamp, 1995.

RODRIGUES, A. Estratégias da Comunicação: questão comunicacional e formas de sociabilidade. Lisboa, Portugal: Presença, 2012.

THOMPSON, J. B. Mídia e Modernidade. Petrópolis: Vozes, 2009.

VARÃO, R.; CUNHA, R. O Conceito de Comunicação em John Dewey: de 1884 a 1927. Comunicologia. Brasília: PUC-DF, out. 2014.

Recebido em: 13 de junbo de 2017 Aceito em: 26 de outubro de 2017 